\title{
NOTAS PARA A HISTÓRIA DA VIOLÊNCIA RURAL, EM PORTUGAL, NA SEGUNDA METADE DO SÉCULO XLX *
}

O processo da violência nas tensões quotidianas da vida social

A cena que se descreve passou-se em Andorinha, aldeia do concelho de Coimbra, num fim de tarde de Setembro de 1869.

Encostado à porta de casa, Manuel de Oliveira conversava. Pela rua acima vinha Manuel Monteiro. As relações entre ambos estavam tensas. "Coisas de mulheres" que lhe tinham feito chegar aos ouvidos. Ao cruzar-se com o grupo não saúda ninguém. Atitude suspeita numa aldeia onde todos se conhecem. "Este homem que passa pella gente e não diz nada..." comenta, em voz alta, Manuel de Oliveira. Foi o suficiente. Voltando-se para trás, com o pau que trazia na mão, Manuel Monteiro descarrega uma forte pancada na cabeça de Manuel de Oliveira. Por segundos tudo se imobiliza. Num ápice, abrem-se portas e janelas e sob o olhar de todos

* Este trabalho foi apresentado no Curso de Verão - História Contemporânea de Portugal-Da Monarquia Constitucional à República, que se realizou, em Coimbra, de 10 a 14 de Setembro de 1990. 
tem lugar uma forte disputa entre os dois homens. "Acomodada a desordem", a população dispersa-se e, ao cair da noite, o silêncio envolvia novamente a aldeia (').

Esta cena, escolhida de entre uma heterogeneidade de casos semelhantes, poderia ter ocorrido em qualquer outra aldeia. Mais do que um lugar, com a sua personalidade e traço distintivo, Andorinha é a referência figurada de todas as outras aldeias que poderiam ter servido de pano de fundo ao conflito entre estes dois homens. Exemplo de que parti para a análise da violência na sociedade rural.

A facilidade com que esta irrompe, a agressividade latente que reinava nos campos, "filet de sang jamais sec" nas expressivas palavras de Elisabeth Claverie e Pierre Lamaison $\left({ }^{2}\right)$, são traços comuns às sociedades rurais do século passado. A opinião de Jean-Claude Chesnais, autor de uma obra intitulada Histoire de la violence en Occident de 1800 à nos jours, é bastante clara quanto a este aspecto $\left({ }^{3}\right)$. Reportando-se às sociedades rurais oitocentistas, afirma este autor a dado passo da citada obra: "elles ne connaissent d'autres formes de répression que la vengeance privée, n'appliquent d'autre règle que la loi du talion, exercée dans sa plus froide brutalité" $\left({ }^{4}\right)$.

Este juízo pode parecer excessivo mas a análise de centenas e centenas de processos correccionais de três comarcas - Coimbra, Montemor-o-Velho e Penacova,de 1858 a 1918-confirmam esta realidade: a sociedade rural era estruturalmente violenta $\left({ }^{5}\right)$.

(1) Arquivo da Universidade de Coimbra (A.U.C.), Comarca de Coimbra, maço n. ${ }^{\circ}$, processo n. ${ }^{\circ} 59$.

() L'impossible mariage - Violence et parenté en Gévaudan $17^{\circ}, 18^{e}$ et $19^{\circ}$ siècles, Hachette, Paris, 1982, p. 22.

() Histoire de la Violence en Occident de 1800 à nos jours, Paris, Éditions Robert Laffont, 1981.

(') Jean-Claude Chesnais, ob. cit., p. 9.

(5) Para um estudo mais aprofundado deste tipo de documentação, metodologia utilizada bem como das conclusões a que a sua análise permitiu veja-se a minha dissertação de doutoramento intitulada Violência, justiça e sociedade rural-Os campos de Coimbra, Montemor-o-Velho e Penacova de 1858 a 1918, Coimbra, Faculdade de Letras, 1990- 
Melhor do que as palavras, os números certificam esta conclusão. Cerca de três terços da criminalidade destas comarcas durante o período atrás considerado, aproximadamente $72 \%$, era constituída por crimes contra pessoas, dentro dos quais sobressaíam as ofensas corporais, distribuindo-se os restantes $25 \%$ por delitos contra a propriedade, sobretudo furtos e danos, e delitos contra a ordem e tranquilidade públicas $\left(^{6}\right)$.

A caracterização económico-social do delinquente comum demonstra, ainda, que este não pertencia a grupos marginais da sociedade. Nada que se assemelhe a sub-grupos ou sub-culturas que tantas sociedades actuais desenvolvem no seu seio e que se caracterizam por níveis de violência sem equivalência com o resto do corpo social. A violência não era aqui nada de excêntrico, um epifenómeno restrito a certas margens ou franjas sociais mas, pelo contrário, atravessava todos ou quase todos os estratos.

Trabalhadores rurais, pequenos proprietários, artífices segmentavam, em termos profissionais e em proporções diversas conforme as comarcas e o peso específico de cada actividade nas estruturas económicas regionais, o mundo da pequena criminalidade.

Os comportamentos violentos também não eram exclusivos do sexo masculino, embora tivessem entre este sexo maior desenvolvimento. De uma forma geral, a mulher manifestava a mesma determinação, espírito combativo e à-vontade nos confrontos que o homem. Para ambos, a violência constituía um instrumento de regulação social, um meio de atingir o outro e, simultaneamente, de o penalizar. A própria emigração masculina, que se intensificou nestas áreas a partir da década de 80 do século passado, ao reforçar o papel da mulher na agricultura, passando esta a desempenhar cargos e funções anteriormente executados pelos homens, terá até

(') Para um total de 1051 processos correccionais, provenientes das comarcas de Coimbra, Montemor-o-Velho e Penacova, 760 (72,3\%) reportam-se a delitos contra pessoas, $189(18,0 \%)$ a delitos contra a propriedade e apenas $102(9,7 \%)$ a delitos contra a ordem e tranquilidade públicas. 
contribuído para agravar a delinquência feminina, que aumenta em particular, as ofensas corporais.

Uma violência, pois, de gestos e palavras, de agressões e injúrias. Homens e mulheres prisioneiros da mesma força de agressão, tanto batendo com uma pedra, como rasgando um lenço, tanto injuriando como dilacerando o corpo com instrumentos que deixam marcas profundas na carne: os sachos, os paus, os fueiros. Mas a violência nem sempre se exprimia através destas formas frontais, revestindo, por vezes, formas indirectas e simbólicas. São exemplo disso, conspurcar com excrementos residências ou actos tendentes a ridicularizar.

Integram-se nesta caracterização todos os rituais de censura social, exercidos sobretudo por jovens: os charivaris, as apupadas, entre outras práticas de controlo da moralidade aldeã. Em sentido estrito, os charivaris destinavam-se a sancionar publicamente a prática das segundas núpcias, sobretudo quando estas ocorriam entre cônjuges com acentuada diferença de idade. Uma interpretação mais alargada tende a identificá-los com qualquer transgressão aos costumes e desvios à moral sexual. Era sob esta segunda fórmula que esta prática transparecia na documentação correccional destas comarcas, censurando-se, fundamentalmente, a imoralidade de algumas raparigas solteiras. Esta intenção é flagrante quer nas apupadas, quer nos descantes, bastante frequentes, nos finais do século passado, em algumas freguesias dos concelhos de Coimbra, Montemor-o-Velho e de Penacova.

Apenas um caso, entre outros. Protegidos pela noite, em Janeiro de 1869, alguns jovens subiram "aos outeiros fronteiros à povoação de Sazes e perturbaram a ordem publica diffamando em altas vozes pessoas de differentes sexos, e mal diziam do credito de algumas raparigas daquelles povos". Altas vozearias, amplificadas pela utilização de funis e acompanhadas pelo disparo de tiros, completavam o sentido contestatário desta manifestação ( ${ }^{7}$ ). Outro caso

(') A.U.C., Comarca de Penacova, maço n. ${ }^{\circ} 1$, processo n. ${ }^{\circ} 73$. 
ainda. Altas horas da noite, em 1879, na Pedrulha, um pequeno grupo de homens concentrara-se à porta de um certo Manuel, cabo da guarda da referida localidade, onde cantaram, acompanhadas à viola e à harmónica, "cantigas desonestas" que denunciavam a situação irregular vivida entre este e uma sua criada, de nome Maria $\left(^{8}\right)$.

Comum a todas estas práticas, o riso - a troça - como forma de censura social e que assenta na subversão da palavra, profundamente ligada à sexualidade e à escatologia. "O riso, esclarece Henri Bergson num ensaio intitulado $O$ riso. Ensaio sobre o significado do cómico, é, antes de tudo, uma correcção. Feito para humilhar, deve dar à pessoa que é objecto dele uma impressão penosa. Através dele se vinga a sociedade das liberdades praticadas para com ela. Não atingiria o seu fim se trouxesse a marca da simpatia ou da bondade" $\left({ }^{9}\right)$. A crueldade, pois, que o riso reveste em todas estas manifestações parece ter a função de penalizar as atitudes e os comportamentos que fogem à regra. Através desta forma primitiva de justiça popular pretendia-se restaurar uma ordem moral tradicional que a fuga aos comportamentos convencionais estabelecera. A violência das palavras tem neste tipo de práticas uma função eminentemente conservadora.

Comportamentos agressivos, brutalidades, rivalidades e xenofobias aldeãs conjugavam-se neste tipo de sociedade onde o auto-controlo emocional, a brandura, não eram culturalmente valorizados. Antes pelo contrário. A violência integrava-se num código de conduta masculino, em que era identificada com a força física, a coragem e a valentia. Sofrer uma afronta sem retorquir, ser desafiado sem ripostar eram interpretados como uma falta de virilidade, cujo culto permanecia muito forte em meio rural. Assim se compreende o comentário proferido, em 1878, por um homem de Quinhendros, aldeia do concelho de Montemor, quando ao 
insultar, por meio de palavras, um seu vizinho este não ripostara às suas provocações: "já não há homens em Quinhendros" $\left({ }^{10}\right)$. A coragem, a temeridade, a "violência", poder-se-ia concluir, definiam um homem. Defrontar um adversário não significava apenas expôr-se à morte, pela qual o homem nutria um certo desprezo mas era, igualmente, uma forma de correr riscos deliberados que possuíam uma carga heróica de forte conotação nobiliárquica.

As próprias hostilidades entre aldeias eram vividas, de igual modo, em termos competitivos de provas de masculinidade entre os rapazes dos respectivos lugares em litígio. Segundo um dos intervenientes de um conflito que opôs, em Julho de 1888, os jovens das localidades de Sargento-Mor e Trouxemil pretendia-se demonstrar "quem eram homens, se os de Sargento-Mor, se os de Trouxemil" ( $\left.{ }^{11}\right)$.

A ética juvenil era, neste aspecto, particularmente rude e brutal. Associá-la aos excessos alcoólicos é já um lugar comum. Com efeito, o crescimento da produção vinícola na segunda metade do século XIX fomentado pela exportação para os mercados europeus e o aumento geral do poder de compra repercutiram-se no aumento do consumo de bebidas alcoólicas, em particular do vinho corrente. A documentação correccional comprova de facto a amplificação deste consumo, sendo bastante frequentes, a partir de 1870, infracções cometidas em estado de embriaguez. As tabernas - cujo número aumenta também no mesmo período, acompanhando o incremento do consumo das bebidas alcoólicas, chegando Anselmo de Andrade a estabelecer, para o início do século XX e para a totalidade do país, a proporção de 1 taberna para 190 habitantes $\left({ }^{12}\right)$ - tornam-se o centro estratégico de uma sociabilidade agressiva e profundamente conflituosa que estava na origem de frequentes desordens e desacatos.

$\left(^{10}\right)$ A.U.C., Comarca de Montemor-o-Velho, maço n. ${ }^{\circ}$ 3, processo sem número.

(11) A.U.C., Comarca de Coimbra, maço n..$^{\circ} 16$, processo n..$^{\circ} 19$.

$\left(^{12}\right)$ Portugal economico - Theorias e factos, Coimbra, nova edição em dois tomos, F. França Amado editores, 1918, p. 130. 
A bebida, diz-se, é má conselheira. Sob a influência das libações etílicas facilmente a mais pequena susceptibilidade provocava cóleras descomedidas. Uma palavra, uma recusa, uma atitude mais insolente eram o suficiente para produzir gestos impulsivos que obedeciam, contudo, a esquemas comuns e a motivações semelhantes. Débitos de bebida, discussões de jogo, insinuações pondo em causa a integridade moral de homens ou mulheres e a falta de cumprimento de "códigos de civilidade" camponesa eram alguns dos motivos mais frequentes de agressão.

Mas, as tabernas eram apenas um dos espaços da violência masculina que, uma forma geral, não tinha lugar marcado, ocorrendo um pouco por todo o lado. O mesmo é válido para a violência feminina. A repartição dos delitos segundo o local da sua ocorrência não conota sexualmente qualquer espaço, seja ele público ou privado, com excepção, talvez, das tabernas para os homens e das fontes, lavadoiros e "enxugadoiros", como referem os documentos, para as mulheres.

A violência "artefacto" ou utensílio social: seus objectivos $e$ finalidades

Porém, nenhuma destas características que esbocei muito grosseiramente eram originais e os camponeses desta região não seriam, provavelmente, nem mais, nem menos violentos do que os seus homólogos do resto do país ou de outras zonas da Europa.

Os estudos históricos têm demonstrado a presença da violência em múltiplos momentos do quotidiano e chamado a atenção para o alto nível de conflituosidade das relações humanas, num mundo e numa época em que os meios jurídicos eram inacessíveis à maioria da população. A evolução para a modernidade estima-se, precisamente, pelo afastamento deste modelo cultural que Norbert Elias traçou já há alguns anos $\left({ }^{13}\right)$. De acordo com este investigador, os

$\left({ }^{13}\right)$ La civilisation des moeurs. Paris, Calmann-Levy, 1973. 
comportamentos violentos eram apenas uma das características da estrutura emocional dos homens de então e que se particularizava, ainda, pelas manifestações exuberantes de sentimentos, o gosto pelos desportos violentos, entre outros aspectos.

A diminuição da violência ter-se-ia acompanhado por alterações subtis em todos estes aspectos representativos da vida psicológica ou sócio-mental, fenómeno multissecular que este autor designou pelo sugestivo nome de civilização de costumes, entendendo-se por tal o seu progressivo abrandamento tendente a aproximar-se de um modelo civilizacional difundido pelas classes superiores.

A presença de uma conflituosidade violenta no seio da sociedade rural não significava, necessariamente, desordem ou subversão e por mais paradoxal que possa parecer, a existência de conflitos nem sempre foi considerada como um factor negativo, de enfraquecimento dos elos sociais. Pelo contrário. Desde os sociólogos clássicos do século XIX (Weber, Simmel, Durkheim) aos mais recentes ramos da sociologia experimental que os conflitos têm sido interpretados como uma forma de socialização dos indivíduos e uma componente, inerente e indissociável, dos grupos estreitos, isto é, quanto mais estreito e limitado é o grupo, mais violento e apaixonado é o conflito. Nesta perspectiva, a conflituosidade, latente ou consumada, é considerada como um elemento normal de sentido positivo da vida dos grupos estreitos ou, como diria Malinowski, "l'agression est un sous-produit de la coopération" $\left({ }^{14}\right)$. É o que parece suceder com as comunidades rurais, caracterizadas por um tipo muito específico de organização da sociabilidade, que os antropólogos designam por interconhecimento, e onde a violência se articula com a solidariedade vicinal e formas de relacionamento muito estreito. p. 44.

$\left({ }^{14}\right)$ Cit. por Lewis A. Coser, Les fonctions du conflit social, Paris, P.U.F., 1982, 
Por outro lado, se o nível de violência é elevado é porque esta se insere entre os valores de uma dada sociedade e se tende a identificar com um certo sentido da sua existência e sobrevivência.

A questão que esta realidade coloca é saber o porquê da violência e como é que esta pôde ocupar um lugar no seio das comunidades rurais sem as pôr em causa. Qual era, afinal, a função da violência? A análise dos seus objectivos, a reconstituição dos motivos que a determinavam permitem avançar neste domínio.

Esta, de uma forma geral, sobrevinha de todos os recantos das relações humanas onde era possível estabelecer-se um conflito de interesses, desde a célula básica da sociedade, a família, até aos elos mais genéricos que ligavam os indivíduos à comunidade de habitantes ou a uma comunidade religiosa. Os motivos articulavam-se, fundamentalmente, em torno de duas coordenadas principais que, em regra, se interrelacionavam: a propriedade, elemento determinante do lugar de cada um na escala social e a honra, valor simultaneamente cultural e social.

Por propriedade pretende-se significar uma relação jurídica abstracta, configurando o poder de disposição sobre todo o tipo de bens, imobiliários ou mobiliários e correspondendo quer a um direito privado, quer a um direito colectivo legitimado pela tradição. Naturalmente, a propriedade fundiária, a terra, constituía o principal pomo das discórdias.

Estas gravitavam em torno de duas questões capitais: as diferentes concepções de propriedade e os limites imprecisos das suas jurisdições. A primeira questão colocava-se, sobretudo, e nas áreas dos campos do Mondego, a propósito dos pastos comuns. Extintos pelo Código Civil de 1867, estes mantinham-se nos usos e costumes, formigando os processos de questões causadas pelos estragos dos gados, de culturas espezinhadas ou danificadas. Tradicionais e bastante representativas do contencioso imobiliário eram as questões envolvendo os limites de propriedade: demarcações, serventias e o uso de águas comuns, resultantes de acordos insufi- 
cientemente estabelecidos quanto à fruição deste recurso hídrico. Todas estas questões, às quais se devem ainda associar diferendos financeiros (dívidas, contas, heranças, partilhas) ou de ordem contratual, atestam a importância desempenhada por factores de ordem material no eclodir de situações conflituais da vida quotidiana. Estas desenvolviam-se, preferencialmente, no quadro restrito das relações de vizinhança ou da família como de uma forma geral toda a violência, independentemente dos motivos que a determinavam.

Num tipo de sociedade onde ter é sinónimo de poder, a propriedade e, em particular, a propriedade fundiária não representava apenas um capital económico mas era condição de acesso a um estatuto e a uma posição prestigiada no seio da comunidade rural. Qualquer atentado a esta, por mais insignificante que fosse, poderia pôrem perigo um estatuto socioeconómico arduamente conseguido. Para quem pouco possuía uma aguilhada de terra a menos ou uma propriedade destruída poderia ser o suficiente para agravar uma situação económica.

Motivações subjectivas que pouco ou nada devem à racionalidade económica justificam, ainda, esta defesa intransigente da propriedade. É o caso da honra que tende a associar o respeito pela propriedade com a auto-consideração e o respeito por si próprio, sendo interpretada qualquer violação à integridade patrimonial como uma afronta pessoal. O mesmo é válido para a instituição familiar, na qual o conceito de honra se fundamenta.

"O prestígio de um homem, a sua reputação, a sua honra, dependem tanto dele como da sua família" esclarece José Cutileiro $\left(^{15}\right)$, e a forma mais comum, nestas áreas, de atacar a soberania e a autoridade masculinas consistia, precisamente, em pôr em causa a irrepreensibilidade dos comportamentos femininos do agregado doméstico que exigiam a fidelidade da esposa, a virgindade das filhas e a castidade da viúva.

$\left(^{15}\right)$ "Honra, vergonha e amigos", Honra e vergonha - Valores das sociedades mediterrânicas, Lisboa, Fundação Calouste Gulbenkian, 1971, p. XVIII. 
Neste tipo de sociedade, onde as pessoas não se podem distinguir pela riqueza ou pelo talento, a consideração dos outros é um valor altamente apreciado, sendo, de facto, a honra o motivo principal de contencioso nestas comarcas e indiferentemente reinvidicada por todos os estratos socioprofissionais, desde os mais abonados aos mais desfavorecidos.

Identificada pelos antropólogos como "o valor que uma pessoa tem aos seus próprios olhos mas também aos olhos da sociedade", a honra e a sua antítese, a vergonha, têm sido consideradas como características dos povos mediterrânicos, se bem que os estudos mais recentes neste domínio tenham demonstrado a sua validade em zonas tão diversas como os estados de Virgínia e Carolina, nos E.U.A., ou na zona da Vendeia, no noroeste de França $\left({ }^{16}\right)$. A honra e a vergonha parecem, sobretudo, estar associadas a um estádio de desenvolvimento das sociedades, atenuando-se com o desenvolvimento das relações capitalistas que impõem novos valores enquanto transformam o estatuto antropológico da violência.

Estes critérios fundamentam um sistema ético que se referencia em função dos conceitos de parecer bem ou parecer mal e, nesta medida, desempenham um papel essencial na estruturação da sociedade rural, ao fixar regras morais, promover ou rejeitar atitudes e ao estabelecer a clivagem entre o consentido e o proibido, entre a norma e o desvio.

Porém, ao instituir um campo próprio e autónomo, o código de honra demarca-se das normas das leis positivas que regulamentam legalmente a sociedade. A não identificação das noções de lícito, tolerado e interdito provoca com regularidade a colisão entre os dois sistemas de regras. Um aspecto esclarecedor desta contradição pode ser exemplificado com a diferença de estatuto ocupado pela violência nos dois sistemas normativos. Admitida e valorizada

$\left({ }^{16}\right)$ Edward L. Ayers, Vengeance and justice. Crime and punishement in the 19 th-century American South, New York, Oxford University Press, Inc., 1984; Bernadette Bucher, "La vaillance et l'honneur - Femmes et codes culturels dans une société rurale atlantique (Vendée)", L'Homme, Paris, Juillet-Septembre 1980, XX (3), pp. 5-31. 
segundo o código de honra que obriga a ripostar a qualquer afronta, sob pena de se cair em vergonha, a violência é reprimida e severamente condenada pela legislação penal. Normal ou natural segundo o código da honra, esta era considerada como um desvio ou anti-natural segundo a lei ou, por outras palavras, contrária às regras normativas criadas pela sociedade burguesa para manter a estabilidade social.

Esta contradição colocava o campesinato num sério dilema. Se a honra impelia ao afrontamento directo, à violência, a lei constrangia à aceitação das regras de um "desarmamento interior" sob pena de intervenção judicial.

Nestas circunstâncias, e face ao agravamento do sistema repressivo português, sobretudo a partir do Código Penal de 1886, a solução adoptada pelo campesinato será a de "utilizar" os tribunais para a resolução dos seus diferendos, increvendo-os na lógica da vingança privada e tornando-os o instrumento mais eficaz de penalizar adversários. Pôr um caso em tribunal vai-se converter numa das formas mais radicais de atacar vizinhos, eliminar rivais ou inimigos, desonrá-los, em suma.

Esta transferência da violência física para "os meios de justiça" como forma de retaliação transparece com muita clareza no testemunho de uma mulher de Verride, em 1888, ofendida na sua dignidade pela linguagem grosseira de um rapaz: "Não me posso medir contigo porque sou mulher; mas olha que se fosse homem talvez pagasses caro insultos que me tens dirigido; também não desejo que nem o meu homem, nem o meu filho se batam contigo; só sim me vingaria de ti pelos meios de justiça que pudesse" ( $\left.{ }^{17}\right)$. Naturalmente, o caso caiu na alçada da justiça e uma multa, custas e selos silenciou, por algum tempo, a língua desbragada do prevaricador.

A lógica da vingança privada persiste, mas adaptada a uma nova conjuntura. A violência, naturalmente, atenua-se. Com efeito, uma

${ }^{17}$ A.U.C., Comarca de Montemor-o-Velho, maço n. ${ }^{\circ}$ 3, processo sem número. 
das consequências mais imediatas do reforço do sistema penal oitocentista posto em execução, sobretudo, no último quartel do século XIX e que se consubstanciou, entre outros aspectos, no aumento das forças policiais, reorganização do sistema prisional com a construção das cadeias penitenciárias e, ainda, o reforço da mentalidade punitiva, foi a atenuação da violência rural, diminuindo, sobretudo a partir da década de 90 do século passado, as ofensas corporais que eram os delitos predominantes. Nesta medida, a instituição judicial pelo carácter coercivo e correctivo que desempenha, tornou-se um instrumento de "abrandamento dos costumes". Outros factores contribuíram, também, para esta pacificação dos costumes. É o caso da emigração, que tem o seu ponto alto, nestas áreas, em 1895, e que vai privar a sociedade rural de muitos dos seus elementos mais insubordinados: os trabalhadores rurais. Com efeito, a emigração parece ter funcionado como um antídoto à violência, que, sem este mecanismo de auto-controlo, seria muito superior.

A ordem no meio do "caos": a organização e ritualização dos conflitos

A violência rural obedece, por conseguinte, a um peculiar sistema de valores, pressupondo um determinado modelo de justiça, em função do qual os actos são praticados. Os próprios furtos ou danos são, por vezes, respostas individualizadas a situações qualificadas como injustas por quem as pratica, detendo o delito a importante função social de restaurar a ordem perturbada e restabelecer o equilíbrio destruído. Cite-se, a título exemplificativo, o caso de um certo jornaleiro, da aldeia do Casal de Fernando, acusado, em 1878, de um furto de 4 galinhas que cometera "por querer por esta forma se [pagar] da quantia de 6000 réis que o queixoso lhe ficou devendo do tempo em que o servio" $\left({ }^{18}\right)$. Um exemplo da utilização

${ }^{(18)}$ A.U.C., Comarca de Coimbra, maço n. ${ }^{\circ} 60$, processo $n .^{\circ} 4$. 
da violência como forma de regulador social ou, como qualificariam alguns autores, "la violence comme artefact".

É esta uma das principais funções da violência na sociedade rural e é através das suas práticas que se ajuda a produzir a ordem social. Contrariamente ao que se seria levado a supor, a violência inscreve-se entre os valores positivos da sociedade rural e é por seu intermédio que se faz a afirmação do direito de propriedade, que se define quem tem direitos sobre as terras, bens ou animais e quem os não tem, que se corrigem os comportamentos ou as fugas as normas, ou se reprova a não conformidade aos valores dominantes. Esta tem na sociedade rural um sentido eminentemente conservador e insere-se entre o arsenal de constrangimentos que visam sempre a manutenção do statu quo.

Ao criar-se a ordem com a desordem, a violência é controlada, contida dentro de certos limites e subordinada a rituais precisos que impediam que se generalizasse e estendesse a todo o corpo social. Neste aspecto, a história da violência é inseparável de uma outra história: a da anti-violência, a história dos mecanismos de controlo e de neutralização dos conflitos que a sociedade rural soube criar para os manter dentro de limites aceitáveis. Entre estes salientava-se a prática de jogos que tinham a função terapêutica de libertação das tendências agressivas, dirigindo-as para o campo neutral e inofensivo das actividades lúdicas. É o caso desse jogo "tipicamente nacional" como lhe chama Ernesto Veiga de Oliveira que era o jogo do pau $\left({ }^{19}\right)$.

Descrito por este especialista como "uma técnica de luta em que a arma é um simples pau direito e liso, da altura aproximada de um homem, empunhado e manejado adequadamente por cada um dos contendores", este jogo apresentava-se sob duas formas diversas: "o jogo-combate, que é uma luta propriamente autêntica e o jogo

(") "O jogo do pau em Portugal", Geographica, Revista da Sociedade de Geografia de Lisboa, Lisboa, VIII, n. ${ }^{\circ} 32$, Outubro de 1972, pp. 54-75. 
desporto, torneio atlético, sem intuitos agressivos", fazendo este autor corresponder a primeira modalidade à região nortenha e a segunda ao sul do país.

$\mathrm{Na}$ prática, esta classificação era mais versátil e, em regra, as duas modalidades coexistiam, transferindo-se da violência lúdica para a violência pura e simples. Era, aliás, sob a dupla forma de torneio competitivo amigável e forma de combate a sério que ojogo do pau transparecia na documentação correccional. Jogar a bem e jogar a mal ou, mais grosseiramente, jogar por brincadeira e jogar à bordoada exprimiam, em termos simples e populares, o esbatimento das fronteiras entre estas formas de luta que se sucediam quase involuntariamente. A facilidade de transição de uma situação para outra, transmutava o pau, que era um elemento normal da indumentária do homem rural, numa verdadeira arma de combate. Com efeito, o pau, que os documentos designam geralmente por pau de pastor, constituía o principal instrumento de agressão masculina em qualquer das comarcas estudadas.

Mas se o ludismo comportava nas suas manifestações a possibilidade de combate para a qual facilmente derrapava, o inverso também era válido e, de igual modo, a violência continha uma dimensão lúdica que transparecia com muita clareza nos combates de paus entre homens de aldeias rivais. Era, de facto, sob a forma de combates ou duelos de paus que as tradicionais rivalidades entre aldeias eram vividas nestas áreas.

Apenas dois exemplos. A 8 de Julho de 1888, quando regressavam da Romaria da Rainha Santa, em Coimbra, alguns trabalhadores de Sargento-Mor, localidade perto de Coimbra, foram surpreendidos, no sítio das Areias, por alguns homens de Trouxemil que aí os esperavam. Hostilidades antigas, "visto a povoação de Sargento-Mor estar desavinda com Trouxemil", estiveram na origem do confronto que se seguiu e que assumiu a forma de um combate de paus. No domingo seguinte, novo conflito entre aldeias. No centro das hostilidades encontravam-se, desta vez, as 
povoações da Pedrulha e da Adémia. A passagem pelo território desta aldeia de alguns rapazes tocando guitarra e cantando canções que "diziam que só a ferro e fogo d'alli sahirião" despoletou tensões latentes que se corporizaram numa violenta batalha de paus entre os rapazes dos respectivos lugares em litígio" $\left({ }^{20}\right)$.

Ao transferir a xenofobia aldeã para o campo do jogo, a sociedade rural inscrevia a violência nas suas próprias estruturas, ritualizando-a, controlando-a e submetendo-a ao cumprimento de regras "que a não obrigava a sair dos limites do jogo". Embora tratando-se de um jogo aparentemente sem regras, o jogo do pau estava organizado quanto às suas técnicas e objectivos. De igual forma assim acontecia com os combates de paus que obedeciam a esquemas comuns e a rituais precisos.

Apoiadas, senão activadas, pelas gerações mais velhas, estas competições entre jovens de aldeias rivais parecem obedecer a uma finalidade política, desempenhando um papel central na dinâmica inter-comunitária. Ao transferir-se para o campo do duelo a xenofobia aldeã, reforçava-se a solidariedade vicinal e a coesão no interior de cada comunidade. À custa, pois, do antagonismo, construía-se a unidade; à custa da desordem, a ordem. Estas violências endógenas longe de porem em causa a sociedade rural, permitiam, pelo contrário, revitalizá-la e assegurar a sua perenidade.

Porém, a ritualização, senão mesmo a organização, destes conflitos não se ficava por aqui. Se, como pensa Elliot J. Gorn, "a forma como os homens lutam, quem participa, quais as regras que são seguidas [...] revela muito acerca da cultura e da sociedade" $\left({ }^{21}\right)$, a análise das zonas corporais atingidas, quer neste tipo específico de luta quer, de uma forma geral, em todos os casos

$\left.{ }^{\left({ }^{2}\right.}\right)$ A.U.C., Comarca de Coimbra, maço n. ${ }^{\circ} 16$, processo $n .{ }^{\circ} 19$ e maço n. ${ }^{\circ} 14$, processo n. ${ }^{\circ} 41$.

${ }^{(21)}$ "Gouge and bite, pull hair and scratch: the social significance of fighting in the Southern Backountry", The American Historical Review, volume 10, number 1, February 1985, p. 18. 
de agressão masculina, evidencia determinadas coordenadas comuns que reenviam a um código de honra masculino.

A cabeça, esse centro vital do eu como lhe chama Robert Muchembled $\left({ }^{22}\right)$, era o alvo predilecto das agressões, recaindo em cerca de $70 \%$ de todas as ofensas corporais. Obviamente, poder-se-ia dizer. A posição vertical adoptada neste tipo de luta expunha-a com facilidade à agressão. Todavia, a violência nunca é cega e não se pode considerar mero acaso que, ao nível da cabeça, as agressões incidissem maioritariamente nos hemisférios posteriores, frontal e parietal. Em contrapartida, a zona anterior, occipital, raramente era atingida. A honra exigia um combate frontal, de homens que se olhavam e mediam nos olhos o que naturalmente se reflectia no plano das agressões corporais. Era a honra que impedia que se atacasse alguém traiçoeiramente, pelas costas; era, ainda, a honra que proibia atacar alguém que não empunhasse um pau.

Por intermédio do jogo, os rapazes aprendiam as condutas e os comportamentos através dos quais se reconheciam os verdadeiros homens. Ao polarizar em termos antagónicos, a honra e a vergonha, a norma e o desvio, o jogo do pau tornava-se um instrumento de moralização do jovem que o induzia a respeitar a ordem e a lei. Nesta perspectiva, o jogo do pau continha uma dimensão civilizadora. Através da interiorização de regras aprendia-se a controlar os excessos. E por detrás de uma brutalidade, por vezes descomedida, perfilava-se a moderação e a modéstia. Os rapazes que se entregavam a brutais batalhas de paus são os mesmos que os processos correccionais surpreendem, noutras ocasiões, escondidos para fumar, por receio à hierarquia paterna, ou que, timidamente, baixam os olhos perante o juiz no tribunal.

Profundamente organizada, a sociedade rural soube criar através do jogo um mecanismo endógeno de controlo da agressividade. 
Um mecanismo que permitindo libertar as pulsões, as loucuras e as ansiedades próprias dajuventude, as utilizava em proveito de toda a comunidade. A diminuição da violência arrastará consigo a petrificaçâo e a morte do jogo do pau que desaparece, entrando no folclore e transformando-se num espectáculo.

As transformações económico-sociais da segunda metade do século XIX vão provocar outro tipo de violências. Violências dirigidas contra a instauração da ordem liberal e que se vão expressar através das contravenções, quer às leis do reordenamento agrícola e hidráulico da Bacia do Mondego, quer às leis das estradas e dos caminhos de ferro quer, ainda, assumindo a forma de oposição ao avanço dos campos de arroz.

Zona tradicional de compáscuo, a supressão deste direito colectivo pelo Código Civil de 1867 abriu caminho a modificações significativas nos Campos do Mondego que se consubstanciaram, entre outros aspectos, na difusão da cultura do arroz. Cultura nova, iniciando-se por volta dos anos 50 do século passado, a orizicultura suscitou, desde o primeiro momento, uma acesa polémica em que se opunham interesses económicos e questões de higiene pública, considerando-se os arrozais prejudiciais à saúde como causadores de epidemias de tipo palúdico. A sua implantação deu azo a verdadeiros conflitos de poder entre os grupos socioeconómicos que exploravam e transformavam os campos do Mondego e as populações das diversas povoações onde esta cultura se disseminava e que se corporizou no afrontamento entre comunidades rurais, representadas pelos seus órgãos dirigentes-juntas de freguesia ou de paróquia e as câmaras municipais - e os proprietários e cultivadores de arroz.

Muito haveria a dizer destes conflitos que associam no mesmo tipo de recusa grande parte do campesinato: a recusa ao rompimento de equilíbrios económicos, sociais e ecológicos que as novas legislações liberais implicavam, como também à decomposição das práticas e dos usos comunitários, postos irreversivelmente em causa pelo Código Civil. 
Independentemente das formas adoptadas, o fim último da violência permanece o mesmo: a manutenção do statu quo.

\section{Em jeito de conclusão:}

Para os criminalistas contemporâneos a violência é um fenómeno de desadaptação económica e cultural. Esta interpretação que repele a agressão para fora do universo social não se aplica aos campos estudados. Nestas áreas a violência fazia parte dos costumes e não pode ser descrita como uma linguagem da transgressão. Esta era, pelo contrário, um dos elementos dinâmicos e estruturadores das relações sociais inter e intra comunidades.

A falta de estudos sobre a violência em Portugal no século XIX impede a generalização deste modelo de comportamento ao resto do país, que deverá apresentar especificidades próprias conforme as zonas ou as áreas em causa. No Alentejo, mais concretamente no distrito de Évora e no mesmo período histórico, estudado por José Pacheco Pereira, a delinquência camponesa apresenta características completamente diferentes, onde sobressaem, entre os delitos praticados, os atentados à propriedade e a ameaça de fogo posto $\left({ }^{23}\right)$.Zona de propriedade concentrada, caracterizando-se o trabalhador rural pela completa ausência de meios de produção, sobretudo terra, a violência terá aqui, provavelmente, uma outra função que não seja a defesa intransigente da propriedade e assumindo uma dimensão classista que não tem na área por mim estudada.

Muito haveria ainda para dizer acerca da violência. Das suas formas e modalidades, da sua ritualização, dos valores que tenta preservar ou, ainda, do modo como esta era encarada pelo poder judicial.

Mas isso já é outra história...

$\left({ }^{23}\right)$ "As lutas sociais dos trabalhadores alentejanos: do banditismo à greve", O Século XIX em Portugal, Análise Social, números 61/62, segunda série, volume XVI, 1980,1. a, pp. 135-156. 